\title{
Nutritional status of adolescent girls in Bangladesh: findings of a community based survey
}

\author{
Kabir Hossen ${ }^{1}$, Fazlur Rahman ${ }^{2}$, Saidur Rahman Mashreky ${ }^{3}$
}

${ }^{1}$ Research Coordinator' Centre for Injury Prevention and Research, Bangladesh (CIPRB), Dhaka, Bangladesh. ${ }^{2}$ Professor and Head of Department of Epidemiology, Bangladesh University of Health Sciences (BUHS) \& Executive Director, Centre for Injury

Prevention and Research, Dhaka, Bangladesh (CIPRB). ${ }^{3}$ Associate Professor, Department of Epidemiology, Bangladesh University of Health Sciences (BUHS) \& Director, Centre for Injury Prevention and Research, Dhaka, Bangladesh (CIPRB).

\section{Abstract}

Poverty, large population, socio- economic inequalities and inadequate access to proper health care facilities are the key causes of under nutrition in Bangladesh. Adolescents are the most vulnerable group for under nutrition and having great consequence as they will be parent in future. Studies on nutritional status of adolescent girls are fewer in number and have great effect for intervention. The objective of this study was to assess the nutritional status and predisposing factors of under nutrition among the adolescent girls in Bangladesh. A community-based crosssectional survey was carried out from July to December 2013. Adolescent girls were the study population. Data was collected by face to face interview at household level. According to BMI category $(\mathrm{kg} / \mathrm{m} 2)$ the prevalence of underweight $(\mathrm{BMI}<18.5)$ was found $65.9 \%$ and as per Gomez Classification (Weight for age), the prevalence of malnutrition was $48.2 \%$ (mild), $23.5 \%$ (moderate) and $2.8 \%$ (severe) categories and finally, as per Water Low Classification wasting found $16.6 \%$ (mild), $3.5 \%$ (moderate) and $0.2 \%$ severe categories. On the other hand, stunting found $39.6 \%$ (mild), $9.2 \%$ (moderate) and $2.3 \%$ (severe) categories. Prevalence of under nutrition was found much higher $(82.3 \%)$ among younger age group ( $\leq 12$ years). Higher prevalence of under-nutrition also found among the functionally illiterate adolescent girls, it was $75.8 \%$ and $51.3 \%$ among illiterate and literate group respectively. In both of the cases difference was statistically significant $(\mathrm{p}<0.001)$. The prevalence of illness found higher among under-weight adolescent girls in last two weeks compare to healthy adolescent girls both in rural and urban settings. This difference also found statistically significant $(\mathrm{p}<0.001)$. Under nourishment found higher among younger and low literate girls. Prevalence of other symptoms is also found higher among them.

Keywords: Nutritional status, Under nutrition, Adolescent girls, Anthropometry, Bangladesh.

\section{Introduction}

The World Health Organization (WHO) defines adolescence as the period in human growth and development that occurs after childhood and before adulthood, from ages 10 to $19 .{ }^{1}$ Generally girls begin their adolescent growth at 9 years of age; the pubertal growth lasts within two to four years, with the average rate of linear growth being $5-6 \mathrm{~cm} /$ year. $^{2}$ Adolescence is a crucial part of life. During this period, adolescents gain up to $50 \%$ of their adult weight, $20 \%$ or more adult height and $50 \%$ of their adult skeletal mass. ${ }^{3}$ Nutrition influences growth and development throughout infancy, childhood and adolescence; it is, however, during the period of adolescence that nutrient needs are the greatest. ${ }^{4}$

About 1200 million adolescent in the world's and about $19 \%$ of the total population faces a series of serious nutritional challenges in developing country. ${ }^{5}$ During shortage of food, most families give more attention that babies are well nourished rather adolescent. Inadequate diet can delay or impair healthy development. Stunting can occur in childhood or during adolescence. In some cultures, girls are fed last and fed least. In girls, poor nutrition can delay puberty and lead to the development of a small pelvis. ${ }^{6}$ Poor nutrition starts before birth, and generally continues into adolescence and adult life and can span generations. Chronically malnourished girls are more likely to remain undernourished during adolescence and adulthood, and when pregnant. They are more likely

\section{Practice Points}

- Girls begin their adolescent growth at 9 years of age; the pubertal growth lasts within two to four years, with the average rate of linear growth being 5-6 $\mathrm{cm} /$ year.

- Nutrition influences growth and development throughout infancy, childhood and adolescence; it is, however, during the period of adolescence that nutrient needs are the greatest.

- During shortage of food, most families give more attention that babies are well nourished rather adolescent and in some cultures girls are fed last and fed least.

- Chronically malnourished girls are more likely to remain undernourished during adolescence and adulthood and when pregnant they are more likely to deliver low birth-weight babies.

- Well-nourished adolescents can make optimal use of their skills, talents and energies and be healthy and responsible citizens and parents of healthy babies tomorrow.

to deliver low birth-weight babies. ${ }^{7}$ If adolescents are well nourished, they can make optimal use of their skills, talents and energies and be healthy and

Correspondence: Kabir Hossen, Research Coordinator, Centre for Injury Prevention and Research, Bangladesh (CIPRB), House B-162, Road 23, New DOHS, Mohakhali, Dhaka-1206, Bangladesh. Email: khossen.ey@gmail.com.

South East Asia Journal of Public Health 2016;6(1):3-7. C 2016 Kabir et al., publisher and licensee Public Health Foundation Bangladesh. This is an Open Access article which permits unrestricted non-commercial use, provided the original work is properly cited. 
responsible citizens and parents of healthy babies tomorrow. To accomplish such a task, and in order to break the intergenerational cycle of malnutrition, a special focus is needed for overcoming adolescent malnutrition. One of the ways to break the intergenerational cycle of malnutrition is to improve the nutrition of adolescent girls prior to conception. ${ }^{8}$ Very little attention has been paid to adolescents so far, and adolescent nutrition has received inadequate attention in research as well as in programming for adolescent health. ${ }^{9}$

Malnutrition among the adolescent girls in the South East Asia has been an exceptionally large and complex problem. Among adolescent, 32\% stunting was found in India and $47 \%$ in Nepal. Low body mass index (BMI) is $53 \%$ in India and $36 \%$ in Nepal. ${ }^{10,11}$ A large numbers of adolescent girls are suffering from malnutrition both in urban and rural areas of Bangladesh. The prevalence of adolescent's stunting is $36 \%$ and low body mass index (BMI) is $50 \%$ in Bangladesh. ${ }^{11,5}$ The average energy intake by rural adolescent girls in Bangladesh is $81 \%$ of the recommended dietary allowance (RDA) for age. ${ }^{5}$ However, little published data exits on dietary intake, anthropometric measurement and energy intake of Bangladeshi low-income family's adolescent girls in the urban and rural groups. This study is therefore helpful in evaluating the nutritional status and stunting (according to WHO reference of BMI $)^{4}$ based on dietary intake and anthropometric variables of adolescents girls of both urban and rural settings. The aims of the study were to assess the nutritional status and its predisposing factors among the adolescent girls in Bangladesh.

\section{Materials and methods}

\section{Place of the study}

The study was conducted in rural and urban areas of four selected districts of Bangladesh. Badargonj upazila (sub-district) of Rangpur district and Mohadevpur upazila (sub-district) of Nowgoan district were the rural setting. Konabari of Gazipur metropolitan city form Gazipur district and Bouniabadh of Dhaka metropolitan city from Dhaka district were selected as urban setting.

\section{Study duration}

From July 2013 to December 2013

\section{Study design}

A cross-sectional study design was adopted in this study.

\section{Study population}

Adolescent girls were the study population of this study.

\section{Sampling}

A multistage simple random sampling was used for selecting adolescent girls in both settings. Firstly, we have purposively selected four upazilas (sub-district)/ metropolitan cities from four districts. In second step 18 villages/mohallas were selected randomly from each Upazilas (sub-district)/metropolitan city and then 6 samples (adolescent girls) were selected randomly from each village but we collected 2 extra samples additionally and interviewed.

\section{Sample size}

Total sample size was 434. Among them, 217 were selected from rural and 217 were from urban.
Data collection procedure

After getting written informed consent from respondent and their guardians, Interview was conducted by using pretested structural questionnaire and the selected adolescent girls were examined clinically for their anthropometrical measurement (height, weight, body mass index).

\section{Study Instrument}

A structured questionnaire was used duly pre-tested to obtain relevant information on socio-economic condition, anthropometric data etc.

\section{Measurements of outcomes}

(i) Anthropometric Measurement: The anthropometric measurements including height and weight of each subject were measured using standard technique. ${ }^{12}$ Trained field research assistants were assigned for measuring. During height measurement we used locally made wooden stadio-metres with a sliding headpiece, and digital weighing scales (TANITA) were used to measure weight. Height was measured to the nearest 0.1 $\mathrm{cm}$ and weight to the nearest $0.5 \mathrm{~kg}$. Each subject was weighed with minimum clothing and no footwear. The scales were carefully handled and periodically calibrated by placing standard calibration weights of 5 $\mathrm{kg}$ iron bars on the scale to ascertain accuracy. If the scale weight did not match the $5 \mathrm{~kg}$ iron bar weight, the scale was calibrated by adjusting its calibration screw. BMI of each participant was computed by using the formula weight $(\mathrm{kg}) /$ height $(\mathrm{m} 2)$ and were graded in different grades of nutritional status according to CDC guideline. $^{12}$ Nutritional status also determined by anthropometric measurement performing standard methods of BMI classification and Gomez Classification $^{13,14}$ as well as Water Low Classification. ${ }^{13}$

(ii) Symptoms of malnutrition in adolescents: The most common symptom is a notable weight loss. For example, those who have lost more than $10 \%$ of their body weight in last three months and are not dieting. This is usually measured using the body mass index (BMI). This is calculated by the weight in kilograms divided by the height in meters squared. A healthy BMI for adults usually lies between 18.5 and 24.9. Color photograph of mal-nutritional sign was provided to interviewer during observation and interviewed.

(iii) Other symptoms include: Weakness of muscles and fatigue, tiredness all day and lack of energy, increased susceptibility to infections, delayed and prolonged healing of even small wounds and cuts, irritability and dizziness, and dryness of skin and hair. ${ }^{15}$ Skin may appear dry and flaky and hair may turn dry and nails may appear brittle and break easily. Persistent diarrhea or long term constipation, irregular menstruation or amenorrhea may present in malnourished women. Depression is common that could be both a cause as well as an effect of malnutrition. ${ }^{15}$

(iv) Socio-demographic information: A household questionnaire was used to collect socio-demographic information.

(v) Age estimation: By asking date of birth, age of first admission in school, which class she is reading, year of first menstruation etc. Field Research Assistant (FRA) were trained how to calculate actual age. 


\section{Data Analysis}

Standard descriptive statistics were used to analyze the malnutrition status of the adolescent girls. Mean, standard deviation (SD) and proportion were used where appropriate. Malnutrition statuses were presented by age, level of literacy and place of residence. Chi Square test was done to see the statistical significance. The test of significance was done at $95 \%$ confidence interval.

\section{Ethical Issue and consideration}

The ethical clearance for the study was obtained from the Centre for Injury Prevention and Research, Bangladesh (CIPRB) Ethical Review Committee. Verbal consent was taken from each the respondents. Verbal consent form was approved by Ethical Review Committee. Anonymity of each interviewee was strictly maintained. The participants of the study were informed that the collected data would be used for the research only.

\section{Results}

A total of 434 adolescent girls were interviewed, among them $217(50 \%)$ adolescent girls were selected from rural and another $217(50 \%)$ were selected from urban area. About $42 \%$ adolescent girls were under $\leq 12$ years' age categories, $37.6 \%$ under 13-14 years' age categories and $20.7 \%$ under $\geq 15$ years' age group. By study area, $44.7 \%$ girls were $\leq 12$ years' category and $41.0 \%$ were 13-14 year category in rural settings. On the other hand, in urban settings it was $38.7 \%$ and $34.1 \%$ respectively. By birth order categories of adolescent girls, most of them both rural and urban area it was $\leq 2$ and by sibling of adolescent girls, it was found between 3-5 both rural and urban area. By occupation category, Majority of adolescent girls were student it was $92.2 \%$ and $73.3 \%$ in rural and urban area respectively. By father occupation most of them were found agriculture in rural area and business in urban area (Table 1).

Considering both rural and urban, according to the BMI category, about $66 \%$ adolescent girls were found under-weight, $0.9 \%$ over-weight and only $0.2 \%$ obese. By Gomez classification, ${ }^{14} 48.2 \%$ adolescent girls were found with mild mal-nourished, $23.5 \%$ moderate mal-nourished and $2.8 \%$ severe mal-nourished. Finally, by the Waterlow Classification, ${ }^{14} 16.6 \%$ found mild wasting, $39.6 \%$ mild stunting, $3.5 \%$ moderate wasting and 9.2\% moderate stunting (Table 2).

Prevalence of under-weight was found very much similar in both urban and rural area. The proportions were, $65.3 \%$ and $64.8 \%$ in rural and urban area respectively. According to the age group, most of the under-weight adolescent girls found under $\leq 12$ years' age category followed by $13-15$ years and then $\geq 15$ years. It was $82.3 \%, 58.1 \%$ and $42.0 \%$ respectively. The proportion is significantly higher compare to another age group $(p=<0.01)$. By education categories, most of the functionally illiterate adolescent girls were found under-weight category compare to literate adolescent girls. It was found $75.8 \%$ and $51.3 \%$ respectively. The difference was fond statistically significant $(p<0.01)$ (Table 3$)$.

Higher prevalence illness found among under-weight adolescent girls compare to healthy weight adolescent girls. Among underweight, 66.7\% suffered from were fever in last two weeks $71.1 \%$ from common cold, $66.7 \%$ from Jaundice $68.8 \%$ suffered from others type of illness. (Table 4). Mal-nutritional symptom found

Table 1: Socio-economic characteristics of adolescent girls in relation to study areas

\begin{tabular}{|c|c|c|c|}
\hline Characteristics & Categories & $\begin{array}{c}\text { Rural (\%) } \\
n=217\end{array}$ & $\begin{array}{c}\text { Urban (\%) } \\
n=217\end{array}$ \\
\hline \multirow{3}{*}{ Age of adolescents girls } & $<12$ years & $97(44.7 \%)$ & $84(38.7 \%)$ \\
\hline & 13-14 years & $89(41 \%)$ & $74(34.1 \%)$ \\
\hline & $>15$ years & $31(14.3 \%)$ & $59(27.2 \%)$ \\
\hline \multirow{3}{*}{ Total family members of respondents } & Three and less & $21(9.7 \%)$ & $30(13.8 \%)$ \\
\hline & Four - five members & $141(65 \%)$ & $118(54.4 \%)$ \\
\hline & Six and above & $55(25.3 \%)$ & $69(31.8 \%)$ \\
\hline \multirow{3}{*}{ Order of respondents } & $<2$ Number & $154(71 \%)$ & $141(65 \%)$ \\
\hline & $3-5$ number & $61(28.1 \%)$ & $67(30.9 \%)$ \\
\hline & $>6$ members & $2(0.9 \%)$ & $9(4.1 \%)$ \\
\hline \multirow{3}{*}{ Sibling of respondents } & Sibling less than 2 & $75(34.6 \%)$ & $62(28.6 \%)$ \\
\hline & Sibling 3 to 5 & $136(62.7 \%)$ & $133(61.3 \%)$ \\
\hline & Sibling more than 5 & $6(2.8 \%)$ & $22(10.1 \%)$ \\
\hline \multirow{2}{*}{ Religion of respondents } & Islam & $199(91.7 \%)$ & $212(97.7 \%)$ \\
\hline & Hindu & $18(8.3 \%)$ & $5(2.3 \%)$ \\
\hline \multirow{3}{*}{ Occupation of respondents } & Student & $200(92.2 \%)$ & $159(73.3 \%)$ \\
\hline & Service & - & $19(8.8 \%)$ \\
\hline & Other & $17(7.8 \%)$ & $39(18 \%)$ \\
\hline \multirow{3}{*}{ Education of respondents } & Functionally illiterate & $103(47.5 \%)$ & $140(64.5 \%)$ \\
\hline & Secondary Incomplete & $108(49.8 \%)$ & $77(35.5 \%)$ \\
\hline & Secondary Complete & $6(2.8 \%)$ & - \\
\hline \multirow{5}{*}{ Fathers occupation of respondents } & Service & $13(6 \%)$ & $28(12.9 \%)$ \\
\hline & Business & $32(14.7 \%)$ & $70(32.3 \%)$ \\
\hline & Agriculture & $105(48.4 \%)$ & $17(7.8 \%)$ \\
\hline & Daily wage earner & $45(20.7 \%)$ & $71(32.7 \%)$ \\
\hline & Others & $22(10.1 \%)$ & $31(14.3 \%)$ \\
\hline
\end{tabular}

South East Asia Journal of Public Health 2016;6(1):3-7 
Table 2: Number of adolescent girls according to BMI category ( $\mathrm{kg} / \mathrm{m} 2)$, Gomez Classification (Weight for age) and WaterLow Classification [Weight for Height (wasting) and Height for Age (stunting)]

\begin{tabular}{|c|c|c|c|c|c|c|}
\hline \multicolumn{2}{|c|}{ BMI category (kg/m2) } & \multicolumn{2}{c|}{ Gomez classification } & \multicolumn{2}{c|}{ Water Low Classification } \\
\hline $\begin{array}{c}\text { Weight } \\
\text { category }\end{array}$ & $\mathbf{n}(\mathbf{\%})$ & $\begin{array}{c}\text { Malnutrition } \\
\text { categories }\end{array}$ & $\mathbf{n}(\mathbf{\%})$ & $\begin{array}{c}\text { Undernutri- } \\
\text { tion categories }\end{array}$ & $\begin{array}{c}\text { Wasting } \\
\mathbf{n}(\%)\end{array}$ & $\begin{array}{c}\text { Stunting } \\
\mathbf{n}(\%)\end{array}$ \\
\hline Underweight & $286(65.9 \%)$ & Normal & $111(25.6 \%)$ & Normal & $346(79.7 \%)$ & $212(48.8 \%)$ \\
\hline Normal weight & $143(32.9 \%)$ & Mild & $209(48.2 \%)$ & Mild & $72(16.6 \%)$ & $172(39.6 \%)$ \\
\hline Overweight & $4(0.9 \%)$ & Moderate & $102(23.5 \%)$ & Moderate & $15(3.5 \%)$ & $40(9.2 \%)$ \\
\hline Obese & $1(0.2 \%)$ & Severe & $12(2.8 \%)$ & Severe & $1(0.2 \%)$ & $10(2.3 \%)$ \\
\hline
\end{tabular}

higher in under-weight adolescent girls compared to healthy weight. Among underweight $66.1 \%$ found shorttempered, $71.9 \%$ found irregular menstruation and $62.1 \%$ found weight loss and felt weak (Table 5).

\section{Discussion}

More than two third adolescent girls in this study found under weight, which is really a crucial public health concern for a nation. Adolescent, a period of transition between childhood and adulthood, occupies a critical position in the life of human beings. This period is characterized by an exceptionally rapid rate of growth. The peak rates of growth are exceeded only during the fetal life and early infancy. ${ }^{16}$ The poor nutritional status of adolescents, especially girls, has important implications in terms of physical work capacity and adverse reproductive outcomes. ${ }^{17}$

Adolescents (aged 10 to 19 years) have specific health and development needs, and many face challenges that hinder their well-being. The findings of this study are kind of similar to some of the previous studies. ${ }^{7}$ Age was found as an associated factor for nutritional status of adolescent girls. Significantly higher prevalence of under-nourished found among the younger age group compare to elder age group. Low literacy also found as contributory factor for undernourishment similar findings observed in other studies.

Disease/illness was a vital factor to effect nutritional status in adolescent girls. It was found, majority of under-nutritional adolescent girls they had tendency fall different types of disease/illness compare to healthy

Table 3: Distribution of under-weight and healthy weight adolescent girls by study area, age and education

\begin{tabular}{|c|c|c|c|}
\hline Categories & Under-weight & Healthy weight & $p$-value \\
\hline \multicolumn{4}{|l|}{ Study Area } \\
\hline Rural & $141(65.3 \%)$ & $75(34.7 \%)$ & \multirow{2}{*}{0.92} \\
\hline Urban & $138(64.8 \%)$ & $75(35.2 \%)$ & \\
\hline \multicolumn{4}{|c|}{ Age group of adolescent girls } \\
\hline$<12$ years & $149(82.3 \%)$ & $32(17.7 \%)$ & \multirow{3}{*}{0.00} \\
\hline 13-14 years & $93(58.1 \%)$ & $67(41.9 \%)$ & \\
\hline$>15$ years & $37(42 \%)$ & $51(58 \%)$ & \\
\hline \multicolumn{4}{|c|}{ Education of adolescent girls } \\
\hline Functionally illiterate & $182(75.8 \%)$ & $58(24.2 \%)$ & \multirow{2}{*}{0.00} \\
\hline Literate & $97(51.3 \%)$ & $92(48.7 \%)$ & \\
\hline
\end{tabular}

Table 4: Diseases reported in last two weeks by under-weight and healthy weight respondents

\begin{tabular}{|l|c|c|}
\hline Diseases & Under-weight & Healthy weight \\
\hline Fever & $42(66.7 \%)$ & $21(33.3 \%)$ \\
\hline Common cold & $27(71.1 \%)$ & $11(28.9 \%)$ \\
\hline Body ache & $5(71.4 \%)$ & $2(28.6 \%)$ \\
\hline Jaundice & $2(66.7 \%)$ & $1(33.3 \%)$ \\
\hline Inching & $1(100 \%)$ & - \\
\hline Diarrhea & $1(33.3 \%)$ & $2(66.7 \%)$ \\
\hline Others & $22(68.8 \%)$ & $10(31.3 \%)$ \\
\hline
\end{tabular}

Table 5: Symptoms of malnutrition in under-weight and healthy weight respondents

\begin{tabular}{|l|c|c|}
\hline Symptoms of malnutrition & Under-weight & Healthy weight \\
\hline Weight loss and feel weak & $95(62.1 \%)$ & $58(37.9 \%)$ \\
\hline Hair fall in large amount & $113(57.4 \%)$ & $84(42.6 \%)$ \\
\hline Skin \& hair appear dry & $42(70 \%)$ & $18(30 \%)$ \\
\hline Nails appear brittle and break easily & $12(75 \%)$ & $4(25 \%)$ \\
\hline Ulcer in the tongue \& corner of the mouth & $34(66.7 \%)$ & $17(33.3 \%)$ \\
\hline Irregular menstruation & $133(71.9 \%)$ & $52(28.1 \%)$ \\
\hline Frequent diarrhea & $19(73.1 \%)$ & $7(26.9 \%)$ \\
\hline Depression & $83(65.4 \%)$ & $44(34.6 \%)$ \\
\hline Short-tempered & $166(66.1 \%)$ & $85(33.9 \%)$ \\
\hline
\end{tabular}

South East Asia Journal of Public Health 2016;6(1):3-7 
adolescent girls. Besides these most of the under-nourished adolescent girls found mal-nutritional syndrome compare to others. Under-nutrition may cause different types of complications that may be life threaten and future burden. ${ }^{7}$ There is no magic pill that can reduce or increase the nutritional status. If the individuals are conscious about nutritional knowledge, nutritional deficiency diseases, nutritional value of food and dietary practices, they can easily overcome those problems and can make sound health and body without wasting excess money.

\section{Limitation of the study}

The study has a number of limitations in relation to sample size and sample selection. Mostly low and lower middle income group were selected. The sample may not represent the national nutritional status of adolescent girls of Bangladesh.

\section{Conclusion and recommendations}

Majority of adolescent girls found under-nourished both in rural and urban areas. Under nourishment found higher among younger and low literate girls. Prevalence illness found higher among undernourished girls. Adolescent nutrition should be considered as a public health problem. An intervention need to be developed to address the adolescent nutrition problems in Bangladesh.

\section{Competing interest}

The authors declare that they have no competing interests.

\section{Authors' contributions}

SRM analyzed and interpreted data and helped to draft the manuscript, co-authored the paper. FR reviewed the final draft of the manuscript, co-authored the paper. MKH wrote the manuscript and prepared the manuscript for submission to the journal. All authors read and approved the final manuscript.

\section{Acknowledgement}

For this study funding was provided to Alive \& Thrive by the Bill and Melinda Gates Foundation. Alive \& Thrive is managed by FHI360.

\section{References}

1. World Health Organisation. Maternal, newborn, child and adolescent health. http://www.who.int/ maternal_child_adolescent/en// (accessed July 2016)

2. Drake VJ. Micronutrient Requirements of Adolescents Ages 14 to 18 Years. http:// lpi.oregonstate.edu/book/export/html/561 (accessed June 2016)

3. Joshi SM, Likhar S, Agarwal SS, Mishra MK, Shukla U. A study of nutritional status of adolescent girls in rural area of Bhopal district. Natl J Community Med 2014; 5(2):191-4.

4. World Health Organization. Nutrition in adolescence: Issues and challenges for the health sector. Geneva: WHO, 2005.
5. Akhter N, Sondhya FY. Nutritional status of adolescents in Bangladesh: Comparison of severe thinness status of a low-income family's adolescents between urban and rural Bangladesh. $J$ Educ Health Promot 2013;2:27.

6. Kumar A. Nutritional Status of Adolescent Girls in Rural Tamilnadu. Natl J Res Community Med 2012;1(1):48-51.

7. Hossain GMM. A Study on Nutritional Status of the Adolescent Girls at Khagrachhari District in Chittagong Hill Tracts, Bangladesh. Am J Life Sci 2013;1(6):278.

8. Mulugeta a, Hagos F, Stoecker B, Kruseman G, Linderhof V, Abraha Z, et al. Nutritional Status of Adolescent Girls from Rural Communities of Tigray, Northern Ethiopia. Ethiop J Heal Dev 2009;23(1).

9. World Health Organization. Improvement of Nutritional Status of Adolescents. New Delhi: WHO, 2002.

10. Bhandari VK, Swami S, College B, Jhal R. Nutritional Status, Dietary Practices and Nutrition Related Beliefs of High School Girls in Urban Area of Bangalore City. IOSR-JNHS 2014;3(3):1-6.

11. Alam N, Roy SK, Ahmed T, Ahmed a. MS. Nutritional status, dietary intake, and relevant knowledge of adolescent girls in rural Bangladesh. J Health Popul Nutr 2010;28(1):8694.

12. Centers for Disease Control and Prevention (CDC). Assessing Your Weight. https:// www.cdc.gov/healthyweight/assessing/ (accessed June 2016)

13. Higashiyama Y, Kubota M, Oshima S, Mibu M, Yasui Y, Nagai A. Assessment of Japanese healthy children's nutritional status using Waterlow classification. Health 2012;04(11):1036-40.

14. Firman G. Classification of Malnutrition in Children. http://www.medicalcriteria.com/site/ home/66-nutrition/275-malnutrition.html (accessed June 2016)

15. Mandal A. Symptoms of malnutrition. http:// www.news-medical.net/health/Symptoms-ofmalnutrition.aspx (accessed June2016)

16. Sengar V, Sharma K. A cross sectional study to assess the physical growth of adolescents in urban Vadodara. Int J Appl Biol Pharm Tech 2012;3(3):160-7.

17. Haboubi GJ, RB S. A comparison of the nutritional status of adolescents from selected schools of South India and UAE: A crosssectional study. Indian $J$ Community $M e d$ 2009;34(2);108-11. 